\title{
From HAVE to HAVE-verbs: Relations and incorporation
}

\author{
Bert Le Bruyn *, Henriëtte de Swart, Joost Zwarts \\ UIL-OTS, Trans 10, 3512JK Utrecht, The Netherlands \\ Received 6 October 2014; received in revised form 6 April 2016; accepted 6 April 2016 \\ Available online 31 May 2016
}

\begin{abstract}
We bring together two lines of research. The first is that of so-called HAVE-verbs, which come with the peculiarity of allowing for bare nominal objects in Norwegian, Catalan, Romanian, etc. These languages normally impose the use of articles in argument position and don't have a generalized incorporation option. The second is that of HAVE itself, a verb that has been claimed to select (predicative) relations rather than arguments in many languages including English. We argue that the literature on relational HAVE provides the key to understanding why HAVE-verbs behave as incorporation verbs. We further show how a unified analysis sheds light on the scopal properties of relational HAVE.

(C) 2016 Published by Elsevier B.V.
\end{abstract}

Keywords: Possession/relationality; Incorporation; HAVE; Qualia Structure

\section{Introduction}

The goal of this paper is to bridge the gap between analyses of (pseudo) incorporation and the literature on relational HAVE. Borthen (2003) first pointed out that verbs like to have, to buy, to wear, ... come with the peculiarity of allowing for bare nominal (count) objects in a number of languages that normally impose the use of articles in argument position (unlike, e.g., Mandarin) and don't have a generalized incorporation option (unlike, e.g., Hungarian).

(1) Han hadde rød ytterfrakk. he had red coat

(Norwegian, Borthen, 2003) 'He had a red coat.'

(2) Forouse frako. s/he-wears frock coat

(Greek, Alexandropoulou, 2013) 'He was wearing a frock coat.'

(3) Ion are copil. Ion has child 'Ion has a child.'

\footnotetext{
* Corresponding author. Tel.: +31302536370.

E-mail addresses: b.s.w.lebruyn@uu.nl (B. Le Bruyn), h.deswart@uu.nl (H. de Swart), j.zwarts@uu.nl (J. Zwarts).
} 
(4) Lleva sombrero.

s/he-wears hat

(Spanish, Espinal and McNally, 2011)

'S/he wears a hat.'

M'acabo de comprar cotxe.

(Catalan, Espinal and McNally, 2011)

REFL.finish.1SG of buy car

'I've just bought myself a car.'

(6) Maria tem carro.

Maria has car

'Maria has a car.'

(Brazilian Portuguese, Cyrino and Espinal, 2011)

Previous analyses have focused on formalizing the semantic and syntactic effects HAVE-verbs give rise to, but haven't tried to explain why HAVE-verbs lend themselves to (pseudo) incorporation in contrast to other verb classes. For illustration purposes, we briefly present the analysis of Espinal and McNally (2011) but the same holds for those presented in Borthen (2003) and Dobrovie-Sorin et al. (2006).

Espinal and McNally (2011) propose that HAVE-verbs are just like regular transitive verbs except for the fact that they can undergo a special shift that allows them to function as incorporation verbs (henceforth IVs):

$$
\begin{aligned}
& \text { Input } \quad \lambda y \lambda x \lambda e\left[V(e) \& A g e n t(e)=x \& \theta(e)=y \& \exists e^{\prime}\left[\text { depend }\left(e, e^{\prime}\right) \& \text { have }\left(e^{\prime}\right) \& \text { havee }\left(e^{\prime}\right)=y\right]\right] \\
& \text { Output } \lambda P \lambda x \lambda e\left[V(e) \& A g e n t(e)=x \& P(\theta(e)) \& \exists e^{\prime}\left[\operatorname{depend}\left(e, e^{\prime}\right) \& \text { have }\left(e^{\prime}\right) \& \text { havee }\left(e^{\prime}\right)=\theta(e)\right]\right] \\
& \text { where } \theta(e) \text { represents the theme of event } e
\end{aligned}
$$

The input in (7) is a regular transitive verb meaning that comes with a dimension of possession, made explicit in the requirement that the event e depends on an event $e^{\prime}$ that is explicitly linked to a have-relation. In the output, the theme argument variable y has been suppressed. It only surfaces indirectly as $\theta(e)$.

If we eliminate the technical complication of theme suppression as well as the event notation, and separate the actual input from the restriction that was built into it, we obtain the basic version of the shifting rule proposed by Espinal and McNally (2011):

$$
\begin{array}{ll}
\text { Input } & \lambda y \lambda x(\mathbf{V}(\mathrm{y})(\mathrm{x})) \\
\text { Output } & \lambda P \lambda x \exists y(\mathbf{V}(\mathrm{y})(\mathrm{x}) \& \mathrm{P}(\mathrm{y})) \\
\text { Restriction } & \text { This rule can only be applied to HAVE-verbs }
\end{array}
$$

The lexical rule in (8) takes a transitive verb and turns it - through existential closure of its internal argument - into a verb that selects predicates rather than arguments. The restriction accounts for the empirical generalization that HAVE-verbs can function as IVs, but does not explain why HAVE-verbs and not verbs like to like or to see behave this way.

This question why there is a natural subclass of languages in which incorporation is restricted to HAVE verbs has not been addressed in the literature. Unsurprisingly, the different formal operations (absorption, restriction, unification, theme suppression) that have been defined to capture the phenomenon of incorporation by Van Geenhoven (1998), Farkas and De Swart (2003), Chung and Ladusaw (2004), Dayal (2011) attain descriptive adequacy of the behavior of HAVE-verbs. However, these operations do not investigate the lexical semantics of HAVE-verbs, and consequently fail at attaining explanatory adequacy of the restriction in (8).

Our answer to the question why HAVE-verbs occur as IVs comes from the literature that has focused its attention on the relational semantics of HAVE (see, e.g., Partee, 1999; Landman, 2004; Sæbø, 2009; Xie, 2014). ${ }^{1}$ We write HAVE rather than have to indicate that we are not talking about English have but rather about a semantic prototype that is instantiated as have in English, avea in Romanian, etc. ${ }^{2}$ The literature on HAVE has characterized it as a light verb that needs the relational content of its object noun to function as a transitive verb. The upshot of this is that HAVE selects relational predicates and not individual arguments. A sentence like (3), e.g., doesn't mean that lon 'owns' a child but rather that there is an individual who stands in the child relation to lon. The simplest way to obtain this interpretation is to start from a relational predicate semantics of copil and to have are establish this relation $\mathbf{R}$ between an individual $\mathbf{v}$ it introduces by itself and its subject w:

\footnotetext{
${ }^{1}$ Very similar ideas about HAVE can be found in the light verb literature (see, e.g., Ritter and Rosen, 1997; Tantos, 2008) as well as outside formal syntax/semantics (see e.g. Buck, 1949; Heine, 1997).

${ }^{2}$ The question whether HAVE can also take the format of to be + dative (as in Latin: mihi est filius, lit. 'to-me is son') is an interesting one but would lead us beyond the scope of this paper.
} 
(9)
【copil】=
$\lambda y \lambda x($ child_of $(y)(x))$
$\llbracket$ are $\rrbracket=$
$\lambda \boldsymbol{R} \lambda \mathrm{w} \exists \mathrm{v}(\mathrm{R}(\mathrm{w})(\mathrm{v}))$
$\llbracket$ Ion are copil $\rrbracket=\exists v($ child-of $($ Ion $)(v))$

In the semantics in (9), copil provides the child relation whereas are introduces an individual while at the same time establishing the child relation between this individual and lon. The prime insight is that HAVE needs the relation included in its object noun and therefore has to function as an IV. This means that - at least for HAVE - we have an intrinsic motivation for giving it an IV analysis. The existential closure we built into are can be the result of theme suppression, absorption or any of the other operations that has been argued to underlie incorporation. As they all boil down to (some version of) existential quantification, we will not commit ourselves to any of the mechanisms proposed in the literature.

As it stands, the analysis of are in (9) is straightforward for (3) but fails to account for any of the other examples in (1)(6), either because they don't contain a relational noun or because they don't involve the verb HAVE. Another problem is that of cross-linguistic variation: even though Romanian allows copil to occur bare after are, English doesn't:

John has *(a) child.

To complicate matters further, Romanian not only allows are to combine with bare nominals but also with full DPs:

$$
\begin{aligned}
& \text { Ion are un copil. } \\
& \text { Ion has a child }
\end{aligned}
$$

A general caveat about $H A V E$-verbs occurring with bare nouns in article languages, is that the existence of this construction does not fit in well with the tendency of such languages to generalize articles with all NPs (Givón, 1981, 1984). The upshot of this is that we expect languages to come with a number of opaque - maybe usage-based - restrictions concerning both the extent of the class of HAVE-verbs allowing for bare nominals and the nouns that can occur with each verb. Laca (1999) e.g. notes that Spanish allows comprar ('to buy') to take casa ('house') as a bare object but not castillo ('castle'). This type of restrictions is beyond the scope of this paper. To remedy to some extent, we focus on Romanian as our prime example of an incorporating language. This choice is motivated by the fact that Romanian has a clear preference for bare nominals in predicate position (Van Peteghem, 1993; Le Bruyn, 2010), which we take as an indication that Romanian has gone less far in generalizing its article use and therefore has less idiosyncratic restrictions at the level of the noun than other languages in (1)-(6). The alternation between (3) and (11) is thus real, and meaningful (cf. section 4.4).

The examples discussed so far indicate that a unified analysis of relational HAVE and incorporating HAVE-verbs faces a number of challenges. As the light verb analysis of HAVE offers us a unique insight into why it selects (articleless) predicates and thus functions as an IV, we believe it is worthwhile pursuing this line of research, and address these challenges.

The paper can be divided into two main parts. In the first, we zoom in on English type relational HAVE and in the second on Romanian type incorporating HAVE-verbs. Part one starts with a presentation of our view on non-relational (section 2) and relational (section 3) nouns, laying the foundations for our analysis of HAVE. Section 4 shows how a relational semantics of HAVE accounts for incorporating HAVE with non-relational nouns, and deals with the presence and absence of articles in (3), (10), (11). In the second part, we extend our analysis of HAVE to HAVE-verbs like to wear, to buy, to want. The assumptions about Qualia Structure we lay out in section 5 provide the basis for the account of incorporation HAVE-verbs in general (section 6). We furthermore complement our semantics with a pragmatic component (section 7) and show that HAVE-verbs don't only constitute a special category in incorporation languages but also in a language like English (section 8).

\section{Non-relational nouns and implicit arguments}

In this section we explain how seemingly non-relational nouns can still have a relational semantics. This is a prerequisite to argue that HAVE selects predicates with a relational dimension. We also use this section to introduce most of the formal machinery we will be using throughout the paper. Given that we assume non-relational nouns have the same type of lexical semantics in languages like English and languages like Romanian, we stick to English examples for expository reasons.

In line with the literature on Qualia Theory (see, e.g., Pustejovsky, 1995), we assume nouns can come with implicit arguments next to their explicit ones. A noun like blog, e.g., comes - as any other one-place predicate - with an explicit, sortal, argument but also comes with at least one implicit argument, viz. the 'creator' argument we know from the agentive role in Qualia Theory. We will refer to this argument as a relational one as it stands in a specific relation to the sortal one. Whether all nouns come with relations in their Qualia Structure remains an empirical matter that lies beyond the scope of 
this paper. The basic test is to check whether the relations in question can be accessed without contextual support (Vikner and Jensen, 2002).

The literature on implicit arguments is a vast one (see, e.g., the survey in Bhatt and Pancheva, 2006 and follow-up work in Francez, 2010; Landau, 2010; Merchant, 2013) but we know of little work on implicit arguments of non-eventive nouns and even less on how we should formalize these. Qualia Theory seems the most extensive theory of implicit arguments of non-eventive nouns to date and below we provide a formally explicit way of conceiving them.

Formalizing implicit arguments is not an easy feat as we need to distinguish them from explicit arguments while at the same time making sure that they are grammatically present. This means we cannot simply assume one of the static representations in (12a) and (12b) but have to go for the dynamic representation in (12c):
a. $\llbracket b \log \rrbracket=\quad \lambda y \lambda x($ blog-created-by $(y)(x))$
b. $\llbracket b \log \rrbracket=\quad \lambda x \exists y($ blog-created-by $(y)(x))$
c. $\llbracket$ blog $_{\text {dynamic }} \rrbracket=\lambda x \mathcal{E} \mathrm{d}_{\mathrm{i}}\left(\uparrow\right.$ blog-created-by $\left.\left(\uparrow \mathrm{d}_{\mathrm{i}}\right)(\mathrm{x})\right)$

(12a) presents blog as having two explicit arguments, an unwarranted move if we want to establish a distinction between explicit and implicit arguments. One might think that $(12 b)$ does the job but this is not the case. Take (13):

John's blog

On the analysis in (12b), it is formally impossible to connect John to the implicit creator argument of blog: the creator argument is existentially closed off and can consequently no longer be targeted. The only way to make sure that (13) can mean the blog created by John while maintaining (12b) as the semantics of blog, is to add a pragmatically motivated relation on top of the creation relation that is already present in blog. This is worked out in (14) where we assume the standard interpretation of John's in (14a) (requiring a relational complement) which, when applied to the one-place predicate (12b), leads to a type-mismatch (14b). Using a standard relational type-shift (e.g. see Barker, 2011) we can turn it into a two-place predicate (14c), in which $R$ is pragmatically specified. Applying (14a)-(14c) leads to (14d) after lambda conversion.
a. $\llbracket J o h n ' s \rrbracket=$ $\lambda \mathbf{R} \mathrm{zz}(\mathbf{R}(\mathrm{John})(\mathrm{z}))$

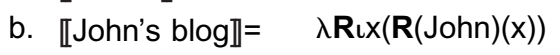
$\lambda x \exists y($ blog-created-by $(y)(x)$ TYPE Mismatch
c. $\llbracket R E L(b l o g) \rrbracket=$
$\lambda z \lambda x \exists y($ blog-created-by $(y)(x) \& R(z)(x))$
(pragm. spec. R)
$\lambda z \lambda x \exists y($ blog-created-by $(y)(x) \& c r e a t e d-b y(z)(x))$
d. $(\lambda$-conversion $)) \quad \iota x(\exists y($ blog-created-by $(y)(x) \&$ created-by $(J o h n)(x)))$

(14d) gets us the required reading of (13) but does so through a pragmatic route: $y$ (the original relational argument of blog) is not semantically equated with John. This limitation stems from the fact that $y$ in (12b) is existentially closed off and can no longer be targeted by John's. The dynamic version in (12c) overcomes this weakness of (12b). The implicit argument is existentially closed off, but a semantically encoded relational interpretation is available anyway, thanks to the dynamic character of the existential quantifier. In what follows, we show how this works.

(12c) is cast in Dynamic Montague Grammar (Groenendijk and Stokhof, 1990; Dekker, 1993), a compositional alternative to early dynamic semantics frameworks (see e.g. Kamp, 1981; Heim, 1982). The general format of the entry is very close to its familiar static counterpart in (12b). The comparison between the two reveals that $\varepsilon$ is the dynamic counterpart of $\exists$ and that in addition to the regular variables $(x, y, \ldots)$, used to define functional lambda-terms, there is a new type of variables represented by $d_{i}$ where $d$ stands for discourse marker. For our present purposes it suffices to note that the $d s$ with subscripts were introduced in Dynamic Montague Grammar to make a notational difference between functional and content material. Variables that are abstracted over count as functional and will therefore always be represented by regular variables. Subscripted variables are bound by dynamic quantifiers and count as content material in the sense that they don't have to undergo any further operation to be interpretable within a proposition. The role of the up arrow in (12c) is to mark a shift from static expressions to dynamic ones. This shift is always made explicit for discourse markers and predicate constants but is left implicit for all functional material as this will have no dynamic role to play. ${ }^{3}$

\footnotetext{
${ }^{3}$ The basic types in Dynamic Montague Grammar are $s, e$, and $t$. We will however follow Dekker (1993) in using shorthand notation where $\varepsilon$ stands for the dynamic counterpart of $e$, and $\tau$ for the dynamic counterpart of $t$. Regular variables $(x, y, \ldots)$ as well as lifted discourse markers (those preceded by the up arrow) are assumed to be of type $\varepsilon$ throughout the paper.
} 
The crucial advantage of (12c) over (12b) is that the former but not the latter allows us to target the relational argument. This is not done by regular binding but rather by updating the information we have about the implicit argument. The static formula in (15) contains an unbound variable (in bold), which occurs outside the scope of the existential quantifiers. The definition of existential quantifiers in Dynamic Montague Grammar extends its scope beyond brackets and conjunctions. As a result, (16) is equivalent to (17):

$$
\begin{aligned}
& \exists x \exists y(\text { blog-created-by }(y)(x)) \& y=J o h n \\
& \varepsilon \mathrm{d}_{1} \varepsilon \mathrm{d}_{\mathrm{i}}\left(\uparrow \text { blog-created-by }\left(\uparrow \mathrm{d}_{\mathrm{i}}\right)\left(\uparrow \mathrm{d}_{1}\right)\right) ; \uparrow \mathrm{d}_{\mathrm{i}} \cong \mathrm{J} \text { ohn } \\
& \varepsilon \mathrm{d}_{1} \varepsilon \mathrm{d}_{\mathrm{i}}\left(\uparrow \text { blog-created-by }\left(\uparrow \mathrm{d}_{\mathrm{i}}\right)\left(\uparrow \mathrm{d}_{1}\right) ; \uparrow \mathrm{d}_{\mathrm{i}} \cong \text { John }\right)
\end{aligned}
$$

Two more notational remarks: ';' and 'œ' stand for the dynamic counterparts of ' $\&$ ' and '=' respectively, and the distinction between discourse markers with Roman and Arabic subscripts reflects the difference between implicit and explicit existentially closed off arguments (Dekker, 1993).

We can also put this dynamic machinery to work to turn implicit relational arguments explicit, an operation we dub explicitation - EXPL for short - and that will play a crucial role in the rest of this paper. ${ }^{4}$ The intuitive gist of the proposal is to add a silent of him behind a noun like blog where him stands for an argument that still needs to be bound. Dynamically, this effect is obtained through the introduction of an equation between the implicit relational argument and a new variable that is abstracted over. The result of explicitation for blog is spelled out in (18):

$$
\llbracket \operatorname{EXPL}\left(\text { blog }_{\text {dynamic }}\right) \rrbracket=\lambda y \lambda x \mathcal{E} d_{i}\left(\uparrow \text { blog-created-by }\left(\uparrow d_{i}\right)(x) ; \uparrow d_{i} \cong y\right)
$$

Blog in (18) is no longer a simple sortal (one-place) expression but has been turned into a relational (two-place) expression. One of the applications for this operation is to make nouns like blog compatible with prenominal genitives like John's. We spell out the semantics we assume for John's in (19) - a dynamic version of (14a) - and work out its composition with (18) in $(20)^{5}$ :

$$
\begin{aligned}
& \text { 【John's } \text { dynamic }_{\text {ic }} \rrbracket=\quad \lambda R_{<\varepsilon,<\varepsilon, \tau>>} \mathrm{ld}_{1}\left(\mathrm{R}(\uparrow \mathrm{John})\left(\uparrow \mathrm{d}_{1}\right)\right) \\
& \llbracket J o h n \text { s }_{\text {dynamic }} \text { blog } \rrbracket=\lambda R_{<\varepsilon,<\varepsilon, \tau>>l d_{1}}\left(R(\uparrow \text { John })\left(\uparrow d_{1}\right)\right) \lambda x \mathcal{E} d_{i}\left(\uparrow \text { blog-created-by }\left(\uparrow d_{i}\right)(x)\right) \\
& \text { (explicitation of blog) } \quad\left(\lambda y \lambda x \varepsilon d_{i}\left(\uparrow \text { blog-created-by }\left(\uparrow d_{i}\right)(x) ; \uparrow d_{i} \cong y\right)\right) \\
& \text { ( } \lambda \text {-conversion) } \quad \operatorname{ld}_{1}\left(\lambda y \lambda x \mathcal{E} d_{i}\left(\uparrow \text { blog-created-by }\left(\uparrow d_{i}\right)(x) ; \uparrow d_{i} \cong y\right)(\uparrow J o h n)\left(\uparrow d_{1}\right)\right) \\
& \text { ( } \lambda \text {-conversion) } \quad \operatorname{ld}_{1}\left(\varepsilon d_{i}\left(\uparrow \text { blog-created-by }\left(\uparrow d_{i}\right)\left(\uparrow d_{1}\right) ; \uparrow d_{i} \cong \uparrow J o h n\right)\right)
\end{aligned}
$$

What John's blog ends up referring to is the unique blog $d_{1}$ that was created by someone $d_{i}$ who is identical to John. Statically, this can be reduced to (21):

$$
\text { ıx(blog-created-by(John)(x)) }
$$

(21) refers to the unique blog whose creator is John, the desired interpretation. The semantics in (21) really specifies John as the creator argument of blog in the semantics, whereas in (14d) this was only done in the pragmatics. This means that the creator argument of blog in (12c) counts as a full-fledged (implicit) argument whereas the creator argument of blog in (12b) doesn't.

Now that the use of explicitation is introduced, we can look at its formal definition:

$$
\begin{aligned}
\llbracket E X P L(P) \rrbracket= & \lambda \mathbf{x} \boldsymbol{\lambda y}\left(\mathbf{P}(\mathbf{y}) ; \uparrow \mathbf{d}_{\mathbf{n}} \cong \mathbf{x}\right) \text { for any one-place predicate } \mathrm{P} \text { including the implicit argument } \mathrm{d}_{\mathrm{n}} \text { where } \\
& n \text { ranges over } i, i i, i i i, i v, \ldots
\end{aligned}
$$

This definition states that explicitation takes a one-place predicate and introduces an equation between one of the implicit arguments contained in the predicate and a new variable that is abstracted over. This is a trick we can play in a dynamic semantics but not in a static one and this is why we can formalize implicit arguments along the lines in (12c) but not along those in (12b).

This section has introduced a way to conceive of non-relational nouns as coming with a relational dimension by formalizing relational arguments included in their Qualia Structure as implicit relational arguments. We have now focused

\footnotetext{
${ }^{4}$ Explicitation makes crucial use of the principle of existential disclosure discussed in Dekker (1993) but adds - as did Dekker in his treatment of relational nouns - an operation of lambda abstraction.

${ }^{5}$ For details about the types we assume, see fn. 4. The type of $R$ in (19) is that of a dynamic relational expression.
} 
on a single Qualia role - the agentive one - but will get back to the other roles later in this paper. We remind the reader that the question whether all nouns come with relations in their Qualia Structure remains an empirical one that lies beyond the scope of this paper. The nouns we use are such that the relations included in them are accessible without contextual support (Vikner and Jensen, 2002).

\section{Relational nouns and implicit arguments}

In the previous section we proposed that non-relational nouns can come with implicit relational arguments and analyzed these as dynamically existentially closed off arguments. In this section, we extend this analysis to classical relational nouns, which have standardly been analyzed as two-place predicates, having both an explicit sortal and an explicit relational argument. By analyzing relational nouns in English as being one-place predicates with implicit arguments, we go against the standard view on relational nouns (see, e.g., Löbner, 1985; De Bruin and Scha, 1988; Barker, 1995).

This idea is not completely new and was, e.g., already proposed by Dekker (1993). ${ }^{6}$ The gist of the proposal is to analyze the relational arguments of relational nouns like child as implicit relational arguments in the same way as we did for the relational arguments included in the Qualia Structure of nouns like blog. This would make (23) into the basic entry we assume for child:

$$
\llbracket \text { child } \rrbracket=\lambda x \varepsilon d_{i}\left(\uparrow \text { child-of }\left(\uparrow d_{i}\right)(x)\right)
$$

The difference between nouns like child and blog resides in where the information about their relational argument is stored: for relational nouns, this is in their regular lexical entry whereas for non-relational nouns, this is in their Qualia Structure. Thus the implicitly relational entry of blog does not contain the predicate blog-of but rather the predicate blogcreated-by, a direct reference to the agentive role from Qualia Structure. For the semantic type of the nouns this difference is irrelevant: both are one-place predicates.

Initial support for giving nouns like blog and child the same basic semantics comes from the fact that both are compatible with of-possessives. Of-possessives traditionally function as a diagnostic for relational nouns, which explains the felicity of (24a) (Barker and Dowty, 1993; Barker, 1995). However, it is easy to construe of possessives with nonrelational nouns, as illustrated by (24b) (see also Rosenbach, 2002):

a. the child of John

b. the blog of Doctor John $\mathrm{H}$. Watson

Another classical argument in favor of downplaying the relational character of relational nouns comes from the fact that relational nouns in a language like English (almost) never require the overt realization of their first argument (De Bruin and Scha, 1988), in contrast to two-place verbs (25a), verbs like to eat being a noteworthy exception (25b) (see a.o. Martí, 2006).
a. ? I lifted.
b. I ate.
I saw a mother.

Where (25a) is felt to be an incomplete sentence, no such feeling is triggered by (26), despite the fact that the first argument of mother (the person she's a mother of) is not realized, parallel to the first argument of lift (the thing/person that was lifted). The same holds for relational nouns in Romanian-type languages:

$$
\begin{array}{llll}
? & \text { Am } & \text { ridicat. } & \\
\text { Am } & \text { I-have lifted } & \\
\text { I-have } & \text { seen } & \text { a } & \text { mamă. } \\
\text { mother }
\end{array}
$$

To complete the argument, we also note that relational nouns in English- and Romanian-type languages can be opposed to relational nouns in languages like Daakaka, the latter always requiring the overt realization of their relational arguments (von Prince, 2012).

\footnotetext{
${ }^{6}$ Dekker's proposal is to be distinguished from the one made by Hellan (1980) and the hypothetical (and rejected) proposal of Partee and Borschev (2003:89-100) in which the relationality of classical relational nouns has to be completely derived in the pragmatics. Dekker's proposal is different in the sense that relationality is included in the nouns' lexical entries.
} 
For other, more formally oriented arguments, we refer the reader to Le Bruyn et al. (2013a,b) where issues of compositionality are used to argue against a two-place analysis of relational nouns. These concern - among others - the interpretation of (29) and (30):

(29) [Context: Mary and Jane work in a team hired to guide young mothers through the first steps of being a mother] Mary to Jane: Have you already taken care of your mother today? John has the only sweet brother.

In (29), the mother that is referred to is not Jane's biological mother but the young mother she has been assigned to. On the standard assumption that your is like John's in requiring a two-place relation as input, this interpretation is difficult to derive on a two-place analysis of mother. The reason is that there is no type mismatch between your and mother that could be held responsible for the reinterpretation of mother as mother that you have been assigned to. On a one-place analysis of mother, the derivation is straightforward because the type mismatch between your and mother can be exploited to derive the relevant reinterpretation.

As for (30), Le Bruyn et al. (2013a,b) show that its standard interpretation - viz. that John is the only person with a sweet brother - cannot be derived on a view that starts from a generalized two-place analysis of relational nouns. The problem lies in the fact that only sweet brother would then refer to John's only sweet brother, John being interpreted as the relational argument of brother in the scope of only. However, we don't want (30) to refer to John's only sweet brother but rather to the only sweet brother in the model. We get back to this example in section 8 where we zoom in on the semantics of the definite article it contains. The full derivation of (30) in the Appendix provides a semantic alternative to the pragmatic account proposed in Le Bruyn et al. (2013a,b).

We conclude that there is sufficient evidence to explore a unified analysis of classical relational nouns as in (31a), familiar from the literature on English have, and non-relational nouns with a relational dimension as in (31b), an example of an incorporated non-relational noun.

$$
\begin{aligned}
& \text { a. John has a child. } \\
& \text { b. Ion are blog. } \\
& \text { Ion has blog } \\
& \text { 'Ion has a blog.' }
\end{aligned}
$$

ROMANIAN

With our assumptions about relationality and nouns in place, we can now turn to HAVE.

\section{The lexical and compositional semantics of $H A V E$}

In this section, we present the lexical semantics of $H A V E$, and show how it composes with relational and non-relational nouns and objects with and without articles.

\subsection{The semantics of HAVE}

We assume the following semantics for HAVE:

$$
\lambda P \lambda z\left(\varepsilon d_{1}(\operatorname{EXPL}(P))(z)\left(\uparrow d_{1}\right)\right)
$$

According to (32), HAVE (i) selects a noun $\mathrm{P}$ with an implicit relational argument, (ii) applies explicitation to it, turning it into a two place predicate with a sortal argument $d_{1}$ and a relational argument $z$, (iii) adds dynamic existential quantification over the sortal argument and (iv) makes the relational argument available for the subject to bind through abstraction. Note that, in contrast to prenominal genitives, we assume HAVE comes with explicitation built into its lexical entry.

To see how (32) combines with relational nouns, we provide the full derivation of (33) in (34):

$$
\begin{aligned}
& \text { lon are copil =(3) } \\
& \text { John has child }
\end{aligned}
$$

ROMANIAN

【lon are copil】

ROMANIAN

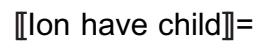

【child $\rrbracket=\quad \lambda x \mathcal{E} d_{i}\left(\uparrow \operatorname{child}-o f\left(\uparrow d_{i}\right)(x)\right)$

【have child $\rrbracket=\quad \lambda P \lambda z\left(\varepsilon d_{1}(\operatorname{EXPL}(P))(z)\left(\uparrow d_{1}\right)\right) \quad\left(\lambda x \mathcal{E d} d_{i}\left(\uparrow \operatorname{child}-o f\left(\uparrow d_{i}\right)(x)\right)\right)$ 


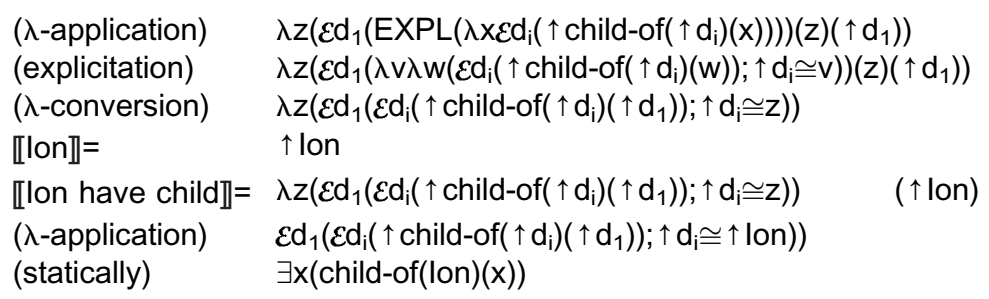

Explicitation takes care of making both the explicit argument $d_{1}$ and implicit argument $d_{i}$ of copil available. The former is existentially closed off, the latter ends up being equated with lon. Ion are copil then means that there is an individual who is a child of someone who is identical to lon. In terms of truth conditions this boils down to saying that there is an individual that stands in the child relation to lon, the desired interpretation.

What happens in (34) is strongly reminiscent of standard incorporation whereby the sortal argument of the noun ends up being identified with the internal argument of the verb. Our proposal involves relational incorporation in which both the sortal and the relational argument of the noun are incorporated.

\subsection{Relational and non-relational nouns}

In the introduction, we pointed out that an analysis in which HAVE selects relational predicates gives us an interesting insight into why incorporation HAVE selects predicates rather than arguments. This insight is maintained in our analysis of HAVE requiring a predicate with an implicitly relational argument but at the same time extended from classical relational nouns like child to non-relational nouns like blog. Our analysis explains why incorporation HAVE is not limited to classical relational nouns and guarantees that the combination with a non-relational noun in (35) has the desired interpretation that there is a blog that was created by lon in (36):

$$
\begin{aligned}
& \text { Ion are blog. } \\
& \text { John has blog }
\end{aligned}
$$

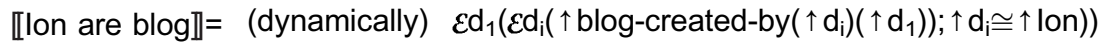

$$
\begin{aligned}
& \text { (statically) } \quad \exists x(\text { blog-created-by }(\text { Ion })(x))
\end{aligned}
$$

ROMANIAN

\subsection{From Romanian to English}

We know that relational HAVE does not show incorporation behavior in every language. The English counterpart of (33) in (37) requires an overt article:

$$
\text { John has *(a) child }
$$

If we want to successfully bring together the literature on HAVE and the literature on incorporation, we have to provide a syntax-semantics interface that deals with the differences between Romanian- and English-type languages (sections 4.3.1 and 4.3.2) while at the same time coming up with independent evidence favoring a unified approach (section 4.3.3).

\subsubsection{Our proposal}

We take the contrast between the Romanian and English examples to be a reflex of the well-known opposition between article and articleless languages. Romanian and English both being article languages, the opposition is a gradual one where English has generalized determiners with NPs further than Romanian. This is inspired by a diachronic view on article development (Givón, 1981, 1984) and exploits the intuition that the syntax and semantics of arguments need not be in a one-to-one correspondence. Chierchia (1998) already argued that some languages need not project DP to guarantee argumenthood (see also Boskovic, 2008). We extend this to variation within languages and assume the flip side here in the sense that we take it that languages may project DP without the resulting DP functioning as a real argument. The most obvious case is the quasi-obligatoriness of the indefinite article in predicate position in English (Partee, 1987). Given that the semantics does not require any article, we assume that the use of an article in English is driven by independent and as yet ill-understood syntactic factors.

Holding syntax responsible for the obligatory appearance of the indefinite article in (37) leaves the semanticist with two tasks. The first is to show how the semantics can deal with the indefinite article, the second is to provide semantic evidence in favor of maintaining that English have is truly an instance of HAVE. 


\subsubsection{English have and the syntax-semantics interface}

The first task is an easy one as we have type-shifting to fall back on. If HAVE requires a predicate but receives an argument, we can rely on standard argument-to-predicate shifts to solve the type mismatch between the verb and its object. In what follows, we work out an analysis of the article variant of (37) where we use the classical BE type-shift to turn the argument a child into a predicate.

We assume a standard generalized quantifier denotation for the indefinite article:

$$
\begin{array}{ll}
\llbracket a \rrbracket= & \lambda Q \lambda P \varepsilon d_{2}\left(Q\left(\uparrow d_{2}\right) ; P\left(\uparrow d_{2}\right)\right) \\
\text { (statically) } & \lambda Q \lambda P \exists x(Q(x) \& P(x))
\end{array}
$$

When combined with the semantics of child, we obtain the result in (39):

$$
\begin{aligned}
& \text { 『a child } \rrbracket=\quad \lambda Q \lambda P \varepsilon \mathrm{d}_{2}\left(\mathrm{Q}\left(\uparrow \mathrm{d}_{2}\right) ; \mathrm{P}\left(\uparrow \mathrm{d}_{2}\right)\right) \quad\left(\lambda x \varepsilon \mathrm{d}_{\mathrm{i}}\left(\uparrow \text { child-of }\left(\uparrow \mathrm{d}_{\mathrm{i}}\right)(\mathrm{x})\right)\right) \\
& \text { ( } \lambda \text {-application) } \lambda P \varepsilon \mathrm{d}_{2}\left(\lambda x \mathcal{E} \mathrm{d}_{\mathrm{i}}\left(\uparrow \text { child-of }\left(\uparrow \mathrm{d}_{\mathrm{i}}\right)(\mathrm{x})\right)\left(\uparrow \mathrm{d}_{2}\right) ; \mathrm{P}\left(\uparrow \mathrm{d}_{2}\right)\right) \\
& \left(\lambda \text {-conversion) } \lambda P \varepsilon d_{2}\left(\varepsilon d_{i}\left(\uparrow \text { child-of }\left(\uparrow d_{i}\right)\left(\uparrow d_{2}\right)\right) ; P\left(\uparrow d_{2}\right)\right)\right. \\
& \text { (statically) } \quad \lambda P \exists x(\exists y(\text { child-of }(y)(x) \& P(x))
\end{aligned}
$$

The problem is that the type of a child is that of an argument whereas HAVE requires a predicate. In order to make the two compatible, we use the standard argument-to-predicate shift known as $B E$. Partee (1987) introduced the $B E$ type-shift to deal with the indefinite article in predicative environments. (40) gives a dynamic version of this shift and (41) works out its effect on the end result of (39). ${ }^{7}$

$$
\begin{array}{ll}
\llbracket B E_{\text {dynamic })} \rrbracket= & \lambda \mathscr{Q}<<\varepsilon, \tau>, \tau>\lambda v(\mathscr{O}(\lambda \mathrm{w}(\mathrm{w} \cong v)) \\
\llbracket B E(\text { a child }) \rrbracket= & \lambda v\left(\lambda P \mathcal{E} \mathrm{d}_{2}\left(\varepsilon \mathrm{d}_{\mathrm{i}}\left(\uparrow \text { child-of }\left(\uparrow \mathrm{d}_{\mathrm{i}}\right)\left(\uparrow \mathrm{d}_{2}\right)\right) ; \mathrm{P}\left(\uparrow \mathrm{d}_{2}\right)\right)(\lambda \mathrm{w}(\mathrm{w} \cong \mathrm{v}))\right. \\
(\lambda-\text { conversion }) & \lambda v\left(\varepsilon \mathrm{d}_{2}\left(\varepsilon \mathrm{d}_{\mathrm{i}}\left(\uparrow \text { child-of }\left(\uparrow \mathrm{d}_{\mathrm{i}}\right)\left(\uparrow \mathrm{d}_{2}\right)\right) ; \uparrow \mathrm{d}_{2} \cong \mathrm{v}\right)\right)
\end{array}
$$

What (41) gives us is a one place predicate with an implicit argument $d_{i}$ and one full-fledged argument $d_{2}$ which is identified with $v$ through the $B E$ type-shift. (42) works out the rest of the derivation:

$$
\begin{aligned}
& \text { 【John has a child》= } \\
& \text { [has a child } \rrbracket=\quad \lambda P \lambda z\left(\varepsilon d_{1}(\operatorname{EXPL}(P))(z)\left(\uparrow d_{1}\right)\right)\left(\lambda v\left(\varepsilon d_{2}\left(\varepsilon d_{i}\left(\uparrow \text { child-of }\left(\uparrow d_{i}\right)\left(\uparrow d_{2}\right)\right) ; \uparrow d_{2} \cong v\right)\right)\right) \\
& \text { ( } \lambda \text {-application) } \quad \lambda z\left(\varepsilon d_{1}\left(\operatorname{EXPL}\left(\lambda v\left(\varepsilon d_{2}\left(\varepsilon d_{i}\left(\uparrow \text { child-of }\left(\uparrow d_{i}\right)\left(\uparrow d_{2}\right)\right) ; \uparrow d_{2} \cong v\right)\right)\right)\right)(z)\left(\uparrow d_{1}\right)\right) \\
& \text { (explicitation) } \left.\quad \lambda z\left(\varepsilon d_{1}\left(\lambda x \lambda y\left(\varepsilon d_{2}\left(\varepsilon d_{i}\left(\uparrow \operatorname{child}-o f\left(\uparrow d_{i}\right)\left(\uparrow d_{2}\right)\right) ; \uparrow d_{2} \cong y\right)\right)\right) ; \uparrow d_{i} \cong x\right)(z)\left(\uparrow d_{1}\right)\right) \\
& \text { ( } \left.\lambda \text {-conversion) } \quad \lambda z\left(\varepsilon d_{1}\left(\varepsilon d_{2}\left(\varepsilon d_{i}\left(\uparrow \text { child-of }\left(\uparrow d_{i}\right)\left(\uparrow d_{2}\right)\right) ; \uparrow d_{2} \cong \uparrow d_{1}\right)\right) ; \uparrow d_{i} \cong z\right)\right) \\
& \left.\llbracket J \text { John has a child } \rrbracket=\lambda z\left(\varepsilon \mathrm{d}_{1}\left(\varepsilon \mathrm{d}_{2}\left(\varepsilon \mathrm{d}_{i}\left(\uparrow \text { child-of }\left(\uparrow \mathrm{d}_{\mathrm{i}}\right)\left(\uparrow \mathrm{d}_{2}\right)\right) ; \uparrow \mathrm{d}_{2} \cong \uparrow \mathrm{d}_{1}\right)\right) ; \uparrow \mathrm{d}_{\mathrm{i}} \cong \mathrm{z}\right)\right)(\uparrow \mathrm{John}) \\
& \text { ( } \left.\lambda \text {-application) } \quad \varepsilon \mathrm{d}_{1}\left(\varepsilon \mathrm{d}_{2}\left(\varepsilon \mathrm{d}_{\mathrm{i}}\left(\uparrow \text { child-of }\left(\uparrow \mathrm{d}_{\mathrm{i}}\right)\left(\uparrow \mathrm{d}_{2}\right)\right) ; \uparrow \mathrm{d}_{2} \cong \uparrow \mathrm{d}_{1}\right)\right) ; \uparrow \mathrm{d}_{\mathrm{i}} \cong \uparrow \mathrm{John}\right) \\
& \text { (statically) } \quad \exists x(\text { child-of(John) }(x))
\end{aligned}
$$

The dynamic semantics we obtain says that there are three individuals $\left(d_{1}, d_{2}\right.$ and $\left.d_{i}\right)$ two of which $\left(d_{1}\right.$ and $\left.d_{2}\right)$ are identical (the effect of the $B E$ shift) and stand in the child relation to the third individual $\left(d_{i}\right)$ who is identical to John (the effect of EXPL). Truth-conditionally, this boils down to saying that there is an individual that stands in the child relation to John, the desired interpretation.

The analysis of (37) in (38)-(42) shows how the contribution of the indefinite article on the argument of have can be neutralized. Thanks to the type-shift $B E$, the difference between English- and Romanian-type languages is reduced to a syntactic difference that has no semantic effect.

\subsubsection{English have as an instantiation of HAVE}

Section 4.3.2 shows how we can undo the semantic contribution of the article, and maintain the HAVE semantics in (32) for English have. We now provide two pieces of evidence that have is an instance of HAVE, despite the overt article on the object in configurations like (37).

Just like Romanian-type HAVE, English have comes with a definiteness restriction (see Partee, 1987; de Hoop 1996; De Swart, 2001):

\footnotetext{
${ }^{7}$ For details about the types we assume, see fn. 4. The type of $\mathscr{Q}$ in $(40)$ is that of a dynamic generalized quantifier.
} 

a. ${ }^{*}$ Ion are copilul. ROMANIAN
Ion has child-the
b. *John has the child.
a. *Ion are blogul. ROMANIAN
Ion has blog-the
b. *John has the blog.

(43) and (44) demonstrate that - even if there's only one child and one blog in the model - the use of the definite article is ungrammatical after HAVE. This can be explained by an interplay between definites and the existential quantification we have built into HAVE. Standard definites presuppose the existence of their referent and we consequently assume that they are pragmatically odd in contexts like the ones created by HAVE in which the existence of their referent is asserted. Built-in existential quantification playing a crucial role in the incorporation behavior of $H A V E$, we take the facts in (43b) and (44b) to be crucial evidence in favor of an analysis of English have along the lines of HAVE. We are aware of the fact that HAVE is sometimes followed by a definite. In most cases, we assume this is due to the fact that we are dealing with another version of $H A V E$, viz. $H A V E_{\text {heavy }}$ (see section 4.4). In some exceptional cases, this is due to the fact that the definites are non-presuppositional (see (30) and its discussion in section 8).

The analysis of English have as an instance of HAVE is further supported by the observation that have forces its object to take narrow scope, a behavior that it shares with incorporating verbs.

$$
\begin{aligned}
& \text { a. Ion nu are soră. } \\
& \text { Ion NOT has sister } \\
& \text { 'Ion doesn't have a sister.' } \\
& \text { b. John doesn't have a sister. }
\end{aligned}
$$

ROMANIAN

(45a) and (45b) cannot be taken to mean that there's a sister lon/John doesn't have but only that lon/John doesn't have a sister at all. To our knowledge, this is an old observation for incorporating languages like Romanian (see e.g. DobrovieSorin et al., 2006) but a new one for non-incorporating languages like English. Our analysis of HAVE derives the scope restriction because it builds existential quantification into the verb, thus making sure that soră/a sister scopes below negation. Given the importance of the role of existential quantification in our analysis, we consider the obligatory narrow scope interpretation of a sister in (45b) to be an important argument in favor of analyzing English have along the lines of HAVE.

\subsubsection{Conclusions on cross-linguistic variation and the syntax-semantics interface}

Even though narrow scope and indefiniteness are crucial ingredients of incorporation, existing incorporation analyses fail to provide a full account of the data listed here. The incorporation analyses familiar from the literature were not designed to deal with relational HAVE and are consequently not equipped to link the subjects of (45a) and (45b) to the implicit relational arguments of their objects. The analysis we propose locates the difference between Romanian- and English-type languages at the level of syntax, the latter but not the former having generalized the obligatory projection of a determiner for singular count objects. The semantics can neutralize the contribution of the determiner, and we have argued that there is independent evidence supporting a unified analysis of HAVE in the two types of languages. This is the decisive step in bringing together the literature on incorporation and the literature on HAVE.

\subsection{Language-internal variation}

Now that we have dealt with the opposition between Romanian- and English-type languages, we can look into variation internal to Romanian-type languages. As we noted in the introduction, Romanian doesn't force the object of HAVE to be bare:

$$
\begin{aligned}
& \text { Ion are (un) copil. } \\
& \text { lon has a child }
\end{aligned}
$$

ROMANIAN

On their standard interpretations, the article and articleless variants of (46) are truth-conditionally equivalent. The derivation of the article variant would be identical to that of its English counterpart (see section 4.3), and lead to the same end result as the articleless variant (see section 4.1), so both state that lon is a parent. The article variant has one more interpretation though, viz. one in which a contextually supplied relation is established between lon and someone else's child. One possible context would be that of a card game involving the members of the Simpson family. The article variant of (46) could then be used to say that lon has a card with Bart, Lisa or Maggie on it. 
Our account of the second reading of the article variant and its absence for the articleless variant relies on the assumption that Romanian avea is ambiguous between the light version of HAVE we have defined in section 4.1 and a 'heavy' version. The former selects predicates and probes the relation included in them, whereas the latter selects arguments and introduces a contextually defined relation. The (static version of the) semantics of $H A V E_{\text {heavy }}$ is provided in (47).

$$
\begin{aligned}
& \llbracket H A \bigvee E_{\text {heavy }} \rrbracket=\lambda y \lambda x(R(x)(y)) \\
& \text { where } R \text { is a contextually defined relation }
\end{aligned}
$$

The article variant of (46) allows for are to be analyzed both as HAVE (giving rise to the child-of interpretation) and as $H A V E_{\text {heavy }}$ (giving rise to the card game interpretation). As for the articleless variant, having a predicate as object, it can only contain an instance of $H A V E$ and consequently only gives rise to the child-of interpretation. ${ }^{8}$ The semantics of $H A V E$ and $H A V E_{\text {heavy }}$ thus accounts for the fine-grained differences between the bare and DP variants of HAVE in Romanian.

Two more remarks are in order about the above facts and analysis. The first is that - setting aside scope considerations the difference in interpretation between the article and articleless variants of (46) constitutes the first attested truth-conditional difference between HAVE followed by a bare noun and HAVE followed by a noun preceded by the indefinite article. This is relevant for the incorporation literature.

Second, the paradigm presented here offers a strong argument in favor of a semantic distinction between the light and heavy versions of HAVE. Sæbø (2009) proposes a unified analysis of the light and heavy version of HAVE by postulating that the difference between the two can be reduced to the contents of an overt or covert Small Clause (henceforth SC). For the light version, the SC contains a covert existence predicate, accounting for the definiteness restriction of this version. For the heavy version, the SC is overt or covert and contains a predicate that is not an existence predicate, thus accounting for the absence of a definiteness restriction. For the card game interpretation of (46), this SC would probably contain a predicate like 'on a card of his'.

The unifying aspect of this analysis is attractive, but maintaining it would make it impossible to account for the difference in interpretation between the article and the articleless variant of (46). An analysis that puts the light and heavy versions of HAVE on a par would have to allow an article predicate to combine with any type of overt or covert SC while restricting articleless predicates to only combine with a covert existence predicate. We do not see a principled way to achieve this. An analysis that maintains a distinction between the two types of $H A V E$, one probing its object for relations, the other the context, clearly fares better with the facts in (46). We note that these facts do not constitute an argument against SC analyses of HAVE per se (see also latridou, 1996; Xie, 2014), but only against the idea that SC analyses would allow us to maintain a unified analysis of HAVE.

\subsection{Conclusion on relational and incorporating HAVE}

In this section we have presented a unified analysis of HAVE in incorporating languages like Romanian and nonincorporating languages like English. We have shown how our analysis can deal with the incorporation potential of HAVE with relational as well as non-relational nouns and how it can deal with cross-linguistic and language-internal variation in the realization or absence of the indefinite article for HAVE. Section 5 will address the final challenge raised in the introduction, viz. how our analysis of HAVE extends to other HAVE-verbs.

\section{From HAVE to HAVE-verbs}

In section 4 we developed an analysis of HAVE that motivated its incorporation behavior on the basis of its lexical semantics. The question we turn to now is whether this analysis extends to verbs like to wear, to buy, to want, which have been classified as HAVE verbs in the incorporation literature.

The question has to be qualified. Under the reasonable assumption that languages are economic in that they minimize redundant lexical items, we do not expect to find more than one lexical item that instantiates HAVE and recycles the relation included in its object noun. The more interesting question is therefore which verbs would be predicted to be such that the relations they encode match the relations included in their objects. If such verbs exist, we could expect them to come with a full version in which they take arguments and encode a fully specified relation and in a light version in which they take predicates and depend on their lexical semantics to specify part of the relation.

\footnotetext{
${ }^{8}$ The interpretation difference between the article and articleless variant of (46) not only holds for a noun like copil ('child') but also for other relational nouns like matușă ('aunt'). Insofar as the counterparts are grammatical in other languages like Norwegian, Catalan, Spanish and Greek, they follow the same pattern: the article variants allow for the two interpretations whereas the articleless variants have an extremely strong preference for the interpretation built on the relation that is included in the noun.
} 
With this interpretation, the question which verbs can qualify as HAVE-verbs is made dependent on the question which types of relations can be expressed by nouns. Here too, some qualification is in order. Most relations expressed by classical relational nouns are fairly specific and it would probably be hard to find a verb denoting a relation that entails or is entailed by the relations included in these nouns. The lack of any real semantic content of HAVE seems to make it into the one verb that can specialize in combining with these relations. To identify other HAVE-verbs, we should consequently look into the relations that can come with non-relational nouns. One such relation is the creator relation that we identified for blog on the basis of its agentive role within Qualia Theory. In this section, we will further explore Qualia Theory as a general theory of implicit relational arguments and end with a list of the relations we expect non-relational nouns to come with.

Qualia Theory is one of the constructs of Generative Lexicon Theory. The latter takes nouns in the lexicon to come with an Argument Structure - their regular entry - and a Qualia Structure. The idea behind Qualia Structure is that the lexicon should provide information about nouns that extends beyond classical entries and that this information conforms to a general format consisting of four perspectives on objects, known as roles. Here we provide what we think is the most common way of presenting roles with - wherever available - the implicit relational arguments they generate.

- The formal role specifies the position of a noun within a taxonomy. A noun like book could, e.g., be classified as an artifact. No implicit arguments come with this role.

- The constitutive role specifies what the objects denoted by the noun consist of. A book can, e.g., be said to consist of pages and a cover. The implicit arguments that can be derived from this role are those that stand in the part-of relation to the noun, the part-of argument.

- The telic role specifies what the objects denoted by the noun are designed for. A book can, e.g., be said to be designed to be read by someone. The implicit argument this role generates is the individual that will put the object denoted by the noun to its intended use, the user argument.

- The agentive role specifies the creator of the objects denoted by the noun. A book can, e.g., be said to have been written by someone. The implicit argument to be derived from this role is the individual that has created the object denoted by the noun, the creator argument.

Qualia Theory holds that these roles should be included in the lexical semantics of the noun. Empirical support comes from the observations in (48) and (49). Qualia Theory was originally designed on the basis of English, but the facts that motivate it carry over to other languages:

(48) a. John started a new book.

b. Ion a început o nouă carte.

Ion has started a new book

ROMANIAN

(49) a. I really want to buy this house but I don't like the front door.

b. Eu chiar vreau să cumpăr această casă, dar nu-mi

I really want to buy this house, but NEG-me

place ușa din față.

pleases door-the of front

ROMANIAN

By including both the agentive and the telic role, Qualia Theory can derive the systematic ambiguity of (48a) and (48b), which can mean that John/lon started a new book as an author/creator or as a reader/user. (49a) and (49b) demonstrate that the definite the front doorlușa din față can be felicitous without previous mention. This follows if we assume front doorl ușa din față is included in the constitutive role of house/casă.

Qualia Theory hasn't been specifically designed to deal with the domain of implicit relational arguments, so it shouldn't come as a surprise that - as it stands - it has been claimed to be too powerful and too weak (see, e.g., Asher and Denis, 2005). We use HAVE and prenominal genitives as our baseline for identifying relations included in nouns. For prenominal genitives, we stick to relations that can be identified out of the blue, thus making sure that we are not talking about contextually supplied relations.

The oddness of (50) an (51) illustrates the apparent overgeneration of Qualia Theory:

?The door has a house.

?the door's house

Under the assumption that the constitutive role generates an implicit door argument for house, we would expect (50) and (51) to be felicitous - contrary to fact. We however don't take these examples to be an argument against Qualia Theory as 
a valid theory for implicit relational arguments. Instead, we conjecture that the relative unacceptability of (50) and (51) is similar to the one we find in the prepositional domain for (52):

$$
\text { ?the tree under the ant }
$$

The unacceptability of (52) is not semantic but pragmatic: in principle we locate smaller things with respect to bigger things and not the other way around. The unacceptability of $(50) /(51)$ and (52) is not different: relating a house to a door is as pragmatically odd as locating trees with respect to ants. We conclude that (50) and (51) don't show that Qualia Theory overgenerates as a theory of implicit relational arguments but that the constitutive role simply doesn't give rise to relations that can easily be exploited by HAVE or prenominal genitives.

Examples where Qualia Theory would appear to undergenerate are the following:

\section{John's keys}

the tree's leaves

Qualia Theory - as it stands - does not provide the necessary means to interpret (53) as being about the keys that belong to John, nor to interpret (54) as being about the leaves that are part of the tree. ${ }^{9}$ One could of course argue that these are meaning components that should be included in the possessive marker but there's also good reason to locate them in the noun and therefore add two extra roles to Qualia Structure, the possessor role and the holistic role, giving rise to the corresponding implicit arguments. ${ }^{10}$

The rationale behind enriching Qualia Structure with the possessor and the holistic role is that both generate relations that are more basic than the use relation the telic role generates. Keys are supposed to be used to open doors, but in order for this to be possible one first has to (temporarily) possess them. In a similar fashion, leaves are put to work by trees to take care of photosynthesis but this is only possible if they are actually part of the tree. The fact that the holistic and possessor role can be seen as underlying the telic role argues in favor of their inclusion in Qualia Structure. ${ }^{11}$

A full overview of the roles we assume is given in (55). The ones giving rise to relations that we expect to be exploited in relational constructions are marked by an asterisk.
formal
constitutive
telic*
agentive*
holistic*
possessor*

A small caveat is in place for relations probed by HAVE, viz. that HAVE comes with a built-in restriction to static relations. This means that a sentence like John has a blog can refer to John having created a blog but not to John creating a blog nor to John reading a blog, unlike John's blog. We leave out this complication in the rest of the paper as we see no deep reason to expect this restriction to carry over to HAVE-verbs in general.

In this section we have argued that identifying potential HAVE-verbs boils down to identifying the verbs that denote relations that match the relations nouns can denote. We have furthermore proposed to adopt a slightly adapted version of Qualia Theory as a general theory of implicit relational arguments included in non-relational nouns. Qualia Theory can thus function as the basis for our predictions about the possible extent of the class of HAVE-verbs.

\footnotetext{
${ }^{9}$ Readers might wonder whether the constitutive role doesn't provide exactly what is needed to account for the relation in (54). This is a longstanding issue in the literature on possessives (see, e.g., Asher and Denis, 2005) but crucially the constitutive role only provides parts, not wholes and can consequently not be used to link the tree as a whole to leaves (at least not on our assumption that the tree is binding an implicit argument provided by leaves).

${ }^{10}$ We don't exclude the possibility that the possessor and holistic role may ultimately be conflated into a single one if (alienable) possession is nothing more than 'falling within the sphere' of someone (Boneh and Sichel, 2010). A similar intuition underlies the use of the term control that is often used in the literature on possession (see, e.g., Vikner and Jensen, 2002; Stassen, 2009). We leave this issue for future work.

${ }^{11}$ Two reviewers point out that it would have been nice if - next to the conceptual argument we develop - we could provide empirical arguments from outside the domain of possession to argue for the addition of the holistic and possessor role. We agree with them but we regretfully have to leave this for future research.
} 


\section{HAVE-verbs: their identity and semantic behavior}

In section 5 we argued that the class of HAVE-verbs is limited to those verbs that match one of the relations included in Qualia Structure:

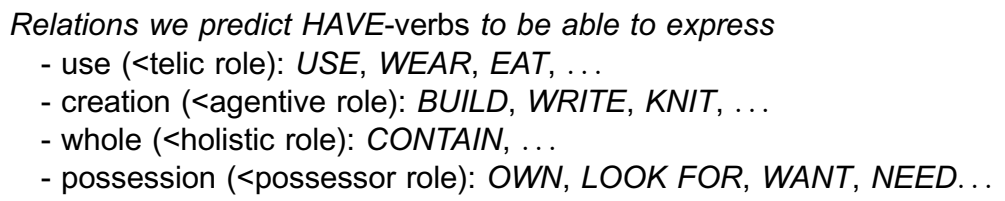

As we indicated before, we assume all HAVE-verbs except HAVE come with some lexical content. This means they don't have to function as IVs and are also likely to have regular entries next to their incorporation entries. Whether or not verbs that fall in these classes behave as IVs consequently remains a lexical matter and cross-linguistic variation in which verbs turn out to behave as IVs cannot be excluded. The list in (56) consequently functions as an upper bound.

An overview of the different classes of HAVE-verbs that have been reported in the literature shows that the list in (56) makes the right predictions. Borthen (2003) points out that Norwegian possession/ownership verbs (e.g., have), usage verbs (e.g., wear), transfer of possession or ownership verbs (e.g., receive, give, buy) and a subclass of intensional verbs based on possession (need, want) allow for bare singular count objects. Dobrovie-Sorin et al. (2006) look into Romanian, Catalan and Spanish and mention have and acquisition verbs as well as some intensional and usage verbs like to look for and to use. Espinal and McNally (2011) and Borik et al. (2012) zoom in on Spanish/Catalan and Brazilian Portuguese respectively and mention the same verb classes as Dobrovie-Sorin et al. (2006). Finally, Lazaridou-Chatzigoga (2011) turns to Greek and reports that the same verbs as the ones found for Norwegian and Romance languages allow for bare objects in Greek as well. Two extra classes of verbs that have been reported to show IV behavior in Norwegian and Greek but that - up till now - haven't been categorized as HAVE-verbs are creation and consumption verbs (like to build and to eat) (cf. Borthen, 2003; Lazaridou-Chatzigoga, 2011).

Some of the verb classes reported were already exemplified in (1)-(6). Here, we provide examples of the other ones: intensional verbs (57-59), creation verbs (60-62), and consumption verbs (63).

Juan busca secretaria.
Juan looks-for secretary
Per a aquest espectacle necessitareu faldilla llarga.
for to this event you-will-need skirt long
lon dorește nevastă tânără.
lon wants wife young
Htizi $\quad$ spiti stin Costa Brava.
She-is-building house in-the Costa Brava
Graphi ghrama sti ghrafomihani.
She-is-writing letter at-the typewriter.
Han striker genser.

Idha mia afisa me ena emvrio pu kapnizi tsigharo. I-saw a poster with a fetus that smokes cigarette
(Spanish, Dobrovie-Sorin et al., 2006)

(Catalan, Espinal, 2010)

(Romanian, Dobrovie-Sorin et al., 2006)

(Greek, Lazaridou-Chatzigoga, 2011)

(Greek, Alexandropoulou, 2013)

(Norwegian, Borthen, 2003)

(Greek, Alexandropoulou, 2013)

It is easy to verify that intensional verbs like NEED and WANT as well as creation and consumption verbs nicely fall into the classes of verbs we expect to be able to function in the same way as HAVE, each of them entailing or being entailed by a relation that is generated by Qualia structure.

To give an idea of the opposition between regular and incorporation entries, we provide these two types of entries for OWN and BUILD, two verbs that qualify as HAVE-verbs given the fact that they match a relation included in their object nouns. The a. versions specify their regular ('heavy') entries, the b. versions their incorporation ('light') entries.

$$
\begin{array}{lll}
\text { a. } & \llbracket O W N_{\text {regular }} \rrbracket= & \lambda x \lambda y(o w n(x)(y)) \\
\text { b. } & \llbracket O W N_{I V} \rrbracket= & \lambda P \lambda z\left(\varepsilon d_{1}\left(\operatorname{EXPL}_{\text {possessor }}(P)\right)(z)\left(\uparrow d_{1}\right)\right)
\end{array}
$$

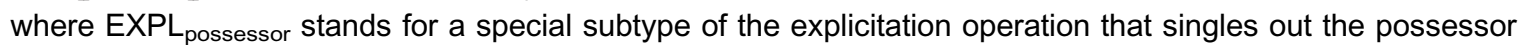
argument of the input noun by requiring the relation that holds between its output arguments to be that of possession 


$$
\begin{array}{lll}
\text { a. } & \llbracket B U I L D_{\text {regular }} \rrbracket= & \lambda x \lambda y(\text { build }(x)(y)) \\
\text { b. } \llbracket B U I L D_{I V} \rrbracket= & \lambda P \lambda z\left(\varepsilon d_{1}\left(\operatorname{EXPL}_{\text {creator-edifice }}(P)\right)(z)\left(\uparrow d_{1}\right)\right)
\end{array}
$$

where $E X P L_{\text {creator-edifice }}$ stands for a special subtype of the explicitation operation that singles out the creator argument of the input noun by requiring the relation that holds between its output arguments to be that of creatorcreated and is restricted to those input nouns that have edifice specified in their formal role

The full versions in (64a) and (65a) take arguments and encode a fully specified relation (own and build). The IV versions in (64b) and (65b) on the other hand select predicates and probe them - through the operation of explicitation - for a relation. By resorting to subtypes of the explicitation operation based on the information in Qualia Structure we are furthermore able to neatly match the relation encoded by the full verb. For verbs like BUY and SELL we would have to make the IV versions slightly heavier than those of OWN and BUILD but the principle behind their semantic make up would be identical.

As we indicated before, we don't expect every language to have both types of entries for each verb. This is a languagespecific lexical matter. What we can provide is a way to test which entries a given verb has. ${ }^{12}$ To establish that a verb has an incorporation entry, one can simply look at whether it combines with bare nouns or not. The realization of $O W N$ in Romanian, e.g., allows for bare nouns and consequently has to be assumed to have the incorporation entry in (64b):

(66) Ion posedă buletin.

lon owns ID

To test whether a given verb also has a regular entry, one should check whether it allows its object to take wide scope over negation. The realization of $O W N$ in Romanian once more qualifies:

$$
\begin{aligned}
& \text { Ion nu posedă un tablou. [ A cumpărat mai multe } \\
& \text { lon not own a painting. He-has bought several } \\
& \text { anul trecut, dar unul anume un l-a putut găsi]. } \\
& \text { year-the past, but one particular not it-has could find. } \\
& \text { 'lon doesn't own a painting. He bought several last year, but one in particular he couldn't find.' }
\end{aligned}
$$

(67) allows for an interpretation according to which there is a particular painting lon doesn't own, despite the fact that he does have other paintings. This is a wide scope reading of un tablou over nu and indicates that poseda has the regular entry in (64a).

\section{HAVE-verbs: their pragmatic behavior}

The type of incorporation associated with HAVE-verbs has been reported to come with a number of properties next to obligatory narrow scope of the verb's object. We briefly outline these properties, based on the work by Espinal and McNally and discuss their status.

(i) Incorporated nominals have a reduced ability to allow for anaphoric pickup of the referent of their sortal argument: (68) Avui porta faldilla. \# La hi vam regular

today she-wears skirt it her we-have given

l'any passat.

(Catalan, Espinal and McNally, 2011)

the year last

'Today she's wearing a skirt. We gave it to her as a present last year.'

(ii) Incorporated nominals have general number: they allow both for singular and plural interpretations. The possibility of a plural interpretation is illustrated in (69):

(69) Busco pis. Un a Barcelona i un a

I-look-for apartment one in Barcelona and one in

Girona.

(Catalan, Espinal and McNally, 2011)

Girona

'I'm looking for apartments. One in Barcelona and one in Girona.'

\footnotetext{
$\overline{12}$ In what follows we restrict ourselves to Romanian-type languages. English-type languages will reenter the picture in section 8.
} 
(iii) Incorporated nominals have restricted modification possibilities. We illustrate for individual-level adjectives (as opposed to kind-level adjectives):

(70) * Té parella alta/malalta.

he-has partner tall/ill

(Catalan, Espinal, 2010)

'He has a tall/ill partner.'

Our analysis - as it stands - predicts none of these properties. Rather than being a shortcoming, this is actually an advantage of our analysis, as properties (i)-(iii) are not stable across languages. Work by Lazaridou-Chatzigoga and Alexandropoulou (in changing configurations) reveals that - at least for Greek - properties (i)-(iii) are not clearly attested.

For (i) they note that the exact counterpart of (68) is indeed not very felicitous but that slight variations are perfectly acceptable:

$\begin{aligned} & \text { Foruse pukamiso } \\ & \text { he-wore htes. } \\ & \text { varkeloni. }\end{aligned}$
Barcelona
'Yesterday he had a shirt on. He had bought it in Barcelona.'

(Greek, Lazaridou-Chatzigoga, 2011)

For (ii), they refer to Alexopoulou and Folli (2010) who note that (72) is infelicitous, despite the fact that it seems a simple variant of (69):

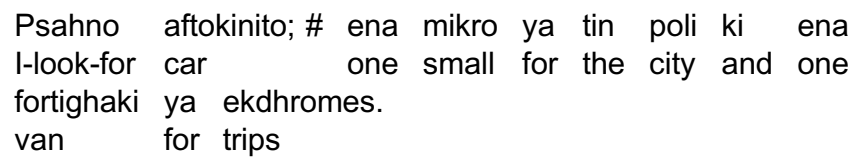

(Greek, Alexopoulou and Folli, 2010)

'I'm looking for a car; a small one for the city and a van for trips.'

For (iii) finally, they find that Greek bare nominal objects combining with IVs show no modification restrictions:

$$
\begin{aligned}
& \text { Ehi psilo gomeno. } \\
& \text { S/he-has tall boyfriend } \\
& \text { 'S/he has a tall boyfriend.' }
\end{aligned}
$$

(Greek, Alexopoulou and Folli, 2010)

The comparison between (68)-(70) and (71)-(73) shows that there is cross-linguistic variation in incorporation with HAVE-verbs. One move would then be to give up the assumption that a unified analysis is possible. We however don't think that this is a particularly insightful move and rather take the comparison to indicate that a unified analysis is possible but should not make any hard predictions about properties (i)-(iii). Our account conforms to this requirement and even comes with an extra perk, viz. that it allows us to understand why properties (i)-(iii) may pop up with HAVE-verbs. This is due to the fact that we predict truth-conditional equivalence between the article and articleless variants of HAVE-verbs. This state-of-affairs is known to trigger pragmatic differentiation (Givón, 1981, 1984; Blutner, 2000; de Swart and Zwarts, 2009) that may but need not end up being entrenched in some languages.

Under the standard assumption that the indefinite article flags the introduction of a new discourse referent, we expect the full DP variant to be the preferred option in all cases in which the individual corresponding to the object is pragmatically relevant. This is obviously the case if anaphoric pickup occurs (property (i)) and in all cases individual-level modification is added to the object (property (iii)). Property (ii) follows under the assumption that the indefinite article is an explicit spell-out of number that is absent from the bare noun.

In this and the previous section, we have argued that our analysis is faring well with the predictions it makes about incorporation with HAVE-verbs. In particular, we have seen that it makes semantic predictions about the stable property of narrow scope and pragmatic predictions about those properties that seem more variable. If these properties turn out to be stable in a given language, we can assume that some (or all) of the pragmatic properties have been entrenched and proceed to fine-tune our analysis with theme suppression as in Espinal and McNally (2011). We have thus succeeded in proposing an analysis that brings out what is common to a number of verb classes across languages without precluding variation. 


\section{HAVE-verbs in English}

In sections 5-7, we have argued that our analysis of HAVE can straightforwardly be extended to HAVE-verbs in general, focusing on Romanian-type languages. What we want to do now is to take the discussion one last step further and argue - as we did for English have in section 4.3.3 - that HAVE-verbs in general are not only special in Romaniantype languages but also in English-type languages. This is the last step in arguing that HAVE-verbs have a special lexical semantics that allows them to take bare nominals more easily than other verbs. Our argumentation will build on the interplay between HAVE-verbs, only and the definite article.

In section 4.3.3 we argued that HAVE comes with a ban on definites that presuppose the existence of their referent. Even though (74) seems to be a counterexample, the interpretation of its negative counterpart in (75) tells us that this is not the case. ${ }^{13}$

John has the only sweet brother.

John doesn't have the only sweet brother.

To our understanding, (74) states that there is a single sweet brother in the model and that it's John's. If the only sweet brother were presuppositional we would expect (75) to mean that there is a single sweet brother in the model but that it's not John's. This is however not the interpretation we get. Rather, (75) means that there are other people than John who also have a sweet brother. The interesting thing about (74) is consequently not that it allows for a definite after HAVE but rather that it allows for the definite to be non-presuppositional, in contrast to the definites we saw before:

(76) *John has the child. (=43b)

(77) *John has the blog. (=44b)

We propose the following explanation. We follow Partee (1987) in assuming a presuppositional and a nonpresuppositional version of the. By Maximize Presupposition we expect the stronger presuppositional version to be the default. ${ }^{14}$ This explains why we don't find sentences like (76) and (77): by Maximize Presupposition we expect the child and the blog to be interpreted presuppositionally, which clashes with the existential environment HAVE creates. The context in (74) is special though in the sense that only overtly marks uniqueness of the object and is therefore incompatible with the indefinite. We conjecture that this is why Maximize Presupposition - a pragmatic principle - can be overruled and the non-presuppositional version of the definite article becomes available. The availability of a non-presuppositional version of the definite in the object position of HAVE is consequently due to the interplay between Maximize Presupposition, the ban on presuppositional definites HAVE comes with and the ban on (non-maximal) indefinites imposed by only. ${ }^{15,16}$ The crucial thing to take from this is that verbs that - like HAVE - come with built-in existential quantification are expected to allow for definites to get a non-presuppositional interpretation when they combine with only. If our analysis of HAVE-verbs is on the right track, we expect this to be one of their traceable properties.

For English HAVE-verbs, we thus predict that they differ from other verbs in allowing for non-presuppositional readings of definite DPs when combined with only. ${ }^{17}$ This prediction is borne out. (78)-(81) give examples of verbs that belong to the class of HAVE-verbs, expressing a use, creation, whole or possession relation:

(78) John didn't make the only pie. ('other people also made a pie so there's no unique pie')

(79) This year didn't contain the only happy day of my life. ('other years also contained happy days so there's no unique happy day of my life')

\footnotetext{
13 The full derivation of $(74)$ is in the Appendix.

14 There are several formulations of Maximize Presupposition on the market. We refer here to the one proposed by Coppock and Beaver (2015).

${ }^{15}$ For reasons that we don't fully grasp yet, the grammaticality of (74) not only depends on the presence of only but also on the presence of sweet. This is reminiscent of an item like any that cannot occur in certain environments without explicit modification. The fact that only seems to come with a notion of widening (it allows for less pragmatic slack than definites) seems to add to the resemblance. We leave this issue for future work.

16 Our account of why the allows for non-presuppositional readings with have is close to that of Coppock and Beaver (2015). In particular their characterization of have as a verb allowing existence to be at issue nicely corresponds to our characterization of have as a verb that comes with built-in existential quantification.

${ }_{17}$ Across languages, there are multiple exclusives (only, sole, unique) that come with their own semantics (see Coppock and Beaver, 2012). Our analysis only makes predictions about English only. Whether or not the counterparts of only in other languages give rise to the same effects is an empirical matter that we leave for future research.
} 
(80) John didn't hold the only glass of champagne. ('other people were also holding glasses of champagne so there's no unique glass of champagne') John isn't smoking the only cigarette. ('other people are also smoking cigarettes so there's no unique cigarette')

The above verbs can be opposed to verbs like to like or to see that don't probe relations in their object's Qualia Structure and are consequently expected not to allow for non-presuppositional readings of the in combination with only. (82) and (83) show that this prediction is borne out:
\#John doesn't like the only fountain in the city. ('other people also like fountains in the city so there's no unique fountain')
\#John didn't see the only house. ('other people also saw houses so there's no unique house')

On the basis of the opposition between the examples in (78)/(81) and (82) to (83) we conclude that we have positive evidence showing that HAVE-verbs have a special lexical semantics involving built-in existential quantification, not only in Romanian-type languages but also in English-type languages. This is strong support for our strategy to link their incorporation potential to their lexical semantics.

\section{General conclusion}

The goal of this paper was to bring together two lines of research. On the one hand, incorporating HAVE-verbs come with the peculiarity of allowing for bare nominal objects in languages like Norwegian, Catalan and Romanian, that in general impose the use of articles in argument position and don't have a generalized incorporation option. On the other hand, English type HAVE has been analyzed as a verb that selects (predicative) relations rather than arguments.

We have argued that a unified analysis of incorporation HAVE and relational HAVE fares well for both classical incorporation languages like Romanian and classical non-incorporation languages like English. Along the way, we rethought the lexical opposition between relational and non-relational nouns (sections 2 and 3 ) as well as the status of the indefinite article with relational HAVE (section 4). We further argued that our analysis - modulo an extended version of Qualia Structure - makes clear predictions about which other verbs can occur as incorporation verbs (section 5) and how we expect them to behave in languages like Romanian (sections 6 and 7) and languages like English (section 8).

Even though we have mainly highlighted how insights on relational HAVE can enrich the literature on incorporation, we are convinced that the reverse also holds. In particular, bringing in the literature on incorporation made it possible to discover that the object of relational HAVE typically takes narrow scope, and that the indefinite article - whose presence has led to various ad hoc moves in the literature on relational HAVE - might simply not have any semantic role to play.

\section{Acknowledgements}

The authors would like to thank the semantics crowd in Utrecht, especially the members of the Weak Referentiality Group, as well as the three anonymous Lingua reviewers, Liz Coppock, Chris Barker, Barbara Partee and audiences at the Workshop on Weak Referentiality and Definitude (Florianópolis), SALT 23 (Santa Cruz), Ana Aguilar-Guevara's defense workshop and Sinn und Bedeutung 19 (Göttingen). Special thanks to lleana Grama, Alexandru Mardale, Stavroula Alexandropoulou, Atle Grønn, Ana Aguilar-Guevara and Toni Bassaganyas for native speaker judgements. The authors furthermore gratefully acknowledge support from NWO (grants \#360-70-340 and \#275-80-006).

\section{Appendix. The derivation of John has the only sweet brother}

We start by spelling out a dynamic version of only that combines with one-place predicates:

(i)

$$
\text { 【only } \rrbracket=\lambda P \lambda x\left(P(x) ; \mathscr{A} \quad d_{2}\left(P\left(\uparrow d_{2}\right) \rightarrow \uparrow d_{2} \cong x\right)\right)
$$

We now combine this with the semantics we assume for sweet brother.

(ii)

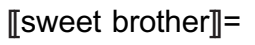
$\lambda y \varepsilon \mathrm{d}_{\mathrm{i}}\left(\uparrow\right.$ sweet-brother-of $\left.\left(\uparrow \mathrm{d}_{\mathrm{i}}\right)(\mathrm{y})\right)$
【only sweet brother $\rrbracket=$
$\lambda P \lambda x\left(P(x) ; d_{2}\left(P\left(\uparrow d_{2}\right) \rightarrow \uparrow d_{2} \cong x\right)\right)\left(\lambda y \varepsilon d_{i}\left(\uparrow\right.\right.$ sweet-brother-of $\left.\left.\left(\uparrow d_{i}\right)(y)\right)\right)$
( $\lambda$-conversion)
$\lambda x\left(\varepsilon d_{\mathrm{i}}\left(\uparrow\right.\right.$ sweet-brother-of $\left.\left(\uparrow \mathrm{d}_{\mathrm{i}}\right)(\mathrm{x})\right) ; \mathscr{A} \mathrm{d}_{2}\left(\varepsilon \mathrm{d}_{\mathrm{ii}}\left(\uparrow\right.\right.$ sweet-brother-of $\left.\left.\left.\left(\uparrow \mathrm{d}_{\mathrm{ii}}\right)\left(\uparrow \mathrm{d}_{2}\right)\right) \rightarrow \uparrow \mathrm{d}_{2} \cong \mathrm{x}\right)\right)$
(statically)
$\lambda x(\exists y($ sweet-brother-of $(\mathrm{y})(\mathrm{x})) \& \forall \mathrm{z}(\exists \mathrm{v}($ sweet-brother-of $(\mathrm{v})(\mathrm{z})) \rightarrow \mathrm{z} \cong \mathrm{x}))$ 
What we have obtained now is an expression that denotes the singleton set containing the only sweet brother in the model. We now continue to let HAVE add existential closure over $\mathrm{x}$ and to equate $\mathrm{d}_{\mathrm{i}}$ with John. The semantic contribution of the is spelled out in (iii) but we don't include it in the full derivation as it would trigger a further (standard) type-shift without adding anything beyond the uniqueness contribution of only.

(iii) 【the

(iv) 【have only sweet brother $\rrbracket=$

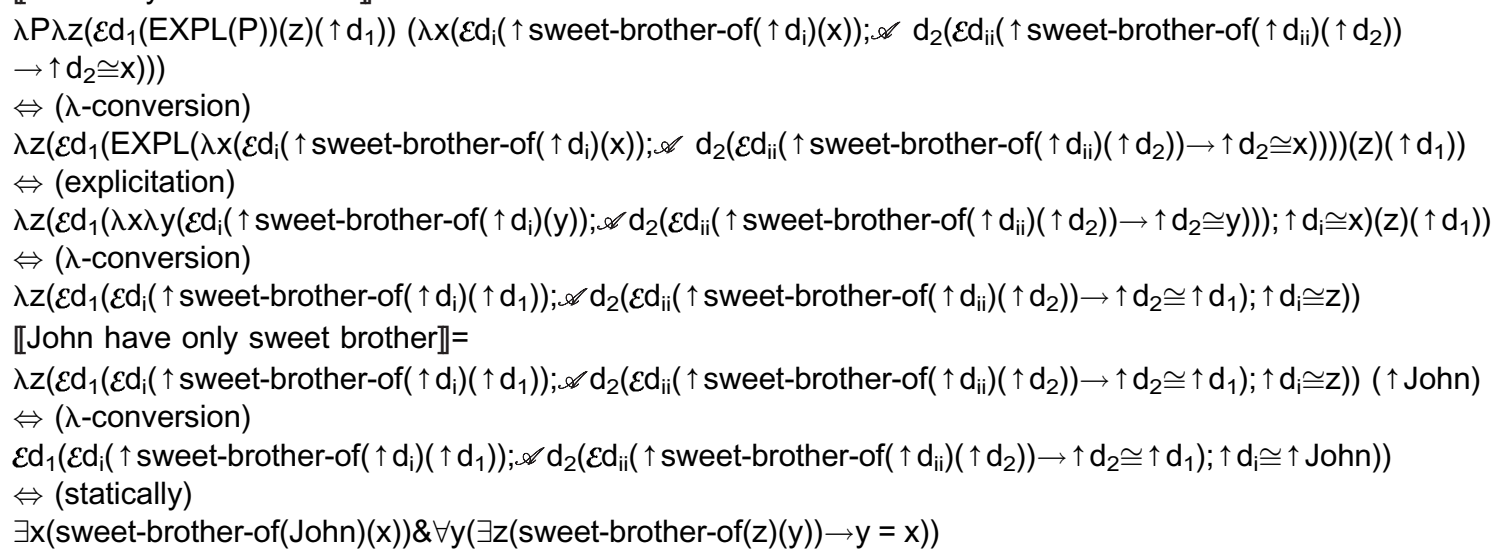

Dynamically, the meaning of John has the only sweet brother is that there is an individual $d_{1}$ who stands in the sweet brother relation to another individual who is identical to John. We furthermore know that there is no individual who is different from $d_{1}$ and also stands to someone in the sweet brother relation. Statically, this is equivalent to John's sweet brother being the only one in the model, the desired interpretation.

One aspect of the derivation deserves closer attention, viz. the explicitation step in which $\mathrm{x}$ is equated with $\mathrm{d}_{\mathrm{i}}$. At first sight it would seem that $x$ could be equated with $d_{i}$ or $d_{i i}$. If this were the case, one might call into question the analysis as it's only the equation with $d_{i}$ that leads to the correct interpretation. Fortunately, the first impression is deceiving as $d_{i i}$ appears in the scope of a universal operator and is consequently not available for dynamic pickup. This reduces the relevant candidates to just one $-d_{i}-$ and makes sure our analysis gets the right result.

\section{References}

Alexandropoulou, S., 2013. The lexical restrictions on verbs with bare nominal complements in Greek and an analysis of such constructions with have-verbs (Master's thesis). Utrecht University.

Alexopoulou, T., Folli, R., 2010. Indefinite topics and the syntax of nominals in Italian and Greek. Paper presented at the 3rd Mediterranean Syntax Meeting, Athens, Greece.

Asher, N., Denis, P., 2005. Lexical ambiguity as type disjunction. In: Third International Workshop on Generative Approaches to the Lexicon. Barker, C., 1995. Possessive descriptions. CSLI Publications, Stanford.

Barker, C., 2011. Possessives and relational nouns. In: Semantics: An International Handbook of Natural Language Meaning

Barker, C., Dowty, D., 1993. Non-verbal thematic proto-roles. In: Proceedings of NELS, vol. 23(1) pp. 49-62.

Bhatt, R., Pancheva, R., 2006. Implicit arguments. The Blackwell Companion to Syntax, vol. 2. pp. 554-584.

Blutner, R., 2000. Some aspects of optimality in natural language interpretation. J. Semant. 17, 189-216.

Boneh, N., Sichel, I., 2010. Deconstructing possession. Nat. Lang. Linguist. Theory 28, 1-40.

Borik, O., Cyrino, S., Espinal, M., 2012. On determiners in languages with and without articles. Paper presented at the workshop 'Languages with and without articles', Paris 8, Paris.

Borthen, K., 2003. Norwegian bare singulars (Doctoral dissertation). Norwegian University of Science and Technology.

Boskovic, Z., 2008. What will you have, DP or NP? In: PROCEEDINGS-NELS, vol. 37(1) p. 101.

Buck, C.D., 1949. A dictionary of selected synonyms in the principal Indo-European languages. University of Chicago Press.

Chierchia, G., 1998. Reference to kinds across language. Nat. Lang. Semant. 6, 339-405.

Chung, S., Ladusaw, W.A., 2004. Restriction and Saturation. MIT Press.

Coppock, E., Beaver, D., 2012. Exclusivity, uniqueness, and definiteness. Empir. Issues Syntax Semant. 9, 59-66.

Coppock, E., Beaver, D., 2015. Definiteness and determinacy. Linguist. Philos. 377-435.

Cyrino, S., Espinal, M., 2011. Object BNs in Brazilian Portuguese. More on the NP/DP analysis. Paper presented at the CSSP 2011, Paris.

Dayal, V., 2011. Hindi pseudo-incorporation. Nat. Lang. Linguist. Theory 29, 123-167.

De Bruin, J., Scha, R., 1988. The interpretation of relational nouns. In: Proceedings of the 26th Annual Meeting on Association for Computational Linguistics, pp. 25-32.

De Swart, H., 2001. Weak readings of indefinites: type-shifting and closure. Linguist. Rev. 18, 69-96.

Dekker, P., 1993. Existential disclosure. Linguist. Philos. 16, 561-587. 
Dobrovie-Sorin, C., Bleam, T., Espinal, M.T., 2006. Bare nouns, number and types of incorporation. In: Non-definiteness and plurality, pp. 51-79. Espinal, M., 2010. Bare nominals in Catalan and Spanish. Their structure and meaning. Lingua 120, 984-1009.

Espinal, M.T., McNally, L., 2011. Bare nominals and incorporating verbs in Spanish and Catalan. J. Linguist. 47, 87-128.

Farkas, D., De Swart, H., 2003. The Semantics of Incorporation. CSLI Publications, Stanford.

Francez, I., 2010. Context dependence and implicit arguments in existentials. Linguist. Philos. 33, 11-30.

Givón, T., 1981. On the development of the numeral 'one' as an indefinite marker. Folia Linguist. Hist. 15 (Historica vol. 2, 1), 35-54.

Givón, T., 1984. Syntax: A Functional-Typological Introduction. John Benjamins, Amsterdam.

Groenendijk, J.A., Stokhof, M.J.B., 1990. Dynamic Montague Grammar. Available from: http://dare.uva.nl/document/2/27376

Heim, I., 1982. The semantics of definite and indefinite noun phrases (Doctoral dissertation). University of Massachusetts.

Heine, B., 1997. Possession: Cognitive Sources, Forces, and Grammaticalization, vol. 83. Cambridge University Press, Cambridge.

Hellan, L., 1980. Toward an Integrated Theory of Noun Phrases. University of Trondheim.

de Hoop, H., 2014. Case Configuration and Noun Phrase Interpretation. Garland.

latridou, S., 1996. To have and have not: on the deconstruction approach. In: Proceedings of WCCFL, vol. 14. pp. 185-201.

Kamp, H., 1981. A theory of truth and semantic representation. In: Formal Semantics - The Essential Readings, pp. 189-222.

Laca, B., 1999. Presencia y ausencia de determinante. In: Gramática descriptiva de la lengua española, pp. 891-928.

Landau, I., 2010. The explicit syntax of implicit arguments. Linguist. Inq. 41, 357-388.

Landman, F., 2004. Indefinites and the Type of Sets. Blackwell.

Lazaridou-Chatzigoga, D., 2011. The distribution and interpretation of bare singular count nouns in Greek. Paper presented at the workshop 'Weak Referentiality'. UiL-OTS, Utrecht, The Netherlands.

Lazaridou-Chatzigoga, D., Alexandropoulou, S., 2013. A corpus study of Greek bare singulars: implications for an analysis. Rev. ABRALIN 12, 233-251.

Le Bruyn, B., 2010. Indefinite articles and beyond. LOT.

Le Bruyn, B., de Swart, H., Zwarts, J., 2013a. Establishing Relations. Available from: https://sites.google.com/site/blebruyn

Le Bruyn, B., de Swart, H., Zwarts, J., 2013b. 'Have', 'with' and 'without'. In: Proceedings of SALT, vol. 23. pp. 535-548.

Löbner, S., 1985. Definites. J. Semant. 4, 279-326.

Martí, L., 2006. Unarticulated constituents revisited. Linguist. Philos. 29, 135-166.

Merchant, J., 2013. Voice and ellipsis. Linguist. Inq. 44, 77-108.

Partee, B., 1987. Noun phrase interpretation and type-shifting principles. Studies in Discourse Representation Theory and the Theory of Generalized Quantifiers, vol. 8. pp. 115-143.

Partee, B., 1999. Weak NPs in have sentences. In: Gerbrandy, J., et al. (Eds.), JFAK [a Liber Amicorum for Johan van Benthem on the occasion of his 50th birthday]. University of Amsterdam, Amsterdam CD-Rom. http://www.illc.uva.nl/j50/

Partee, B., Borschev, V., 2003. Genitives, relational nouns, and argument-modifier ambiguity. Modifying Adjuncts, vol. 4. pp. 67-112.

von Prince, K., 2012. Nominal possession in Daakaka: transitivizing vs. linking. In: Proceedings of AFLA, vol. 18.

Pustejovsky, J., 1995. The Generative Lexicon. MIT Press, Cambridge.

Ritter, E., Rosen, S.T., 1997. The function of have. Lingua 101, 295-321.

Rosenbach, A., 2002. Genitive Variation in English: Conceptual Factors in Synchronic and Diachronic Studies, vol. 42. Walter de Gruyter.

Sæbø, K.J., 2009. Possession and pertinence: the meaning of have. Nat. Lang. Semant. 17, 369-397.

Stassen, L., 2009. Predicative Possession. Oxford University Press, Oxford.

de Swart, H., Zwarts, J., 2009. Less form-more meaning: why bare singular nouns are special. Lingua 119, $280-295$.

Tantos, A., 2008. Computing Events in Discourse: A Case Study Involving Light "have" (Doctoral dissertation). University of Konstanz.

Van Geenhoven, V., 1998. Semantic Incorporation and Indefinite Descriptions: Semantic and Syntactic Aspects of Noun Incorporation in West Greenlandic. CSLI Publications.

Van Peteghem, M., 1993. La détermination de l'attribut nominal: étude comparative de quatre langues romanes (français, espagnol, italien, roumain). Brepols.

Vikner, C., Jensen, P.A., 2002. A semantic analysis of the English genitive. Interaction of lexical and formal semantics. Stud. Linguist. 56, 191-226.

Xie, Z., 2014. The degree use of the possessive verb yǒu in Mandarin Chinese: a unified analysis and its theoretical implications. J. East Asian Linguist. 23, 113-156. 